\title{
Conducting market research using the Internet: the case of Xenon Laboratories
}

Andy Lockett, The University of Nottingham Business School, Nottingham, UK

Ian Blackman, The University of Nottingham Business School, Nottingham, UK

\section{Final Draft Submitted to : Journal of Business and Industrial Marketing}

Published: Vol. 19, no. 3, 2004 pp: 178-187

\section{Acknowledgements}

The constructive and helpful insights of Chris Holland, Pete Naudé and two anonymous reviewers are acknowledged with thanks. Any remaining errors are the authors' own.

\begin{abstract}
The way market research is conducted has changed dramatically over the past 30 years, as a result of both the development of the prevailing view of best practice and the state of technology available to researchers. While it is clear that the World Wide Web (WWW) will increasingly be used as a medium for conducting market research, the full implications of this new channel are not yet fully understood. This paper examines the potential for an Internet-based financial services firm (Xenon Laboratories) to analyse conduct market research using the WWW. The case demonstrates that, by employing a novel approach to market research, Xenon Laboratories is in a unique position to understand the charging structures in its market, the market for international payments using credit or charge cards. In doing so, the paper highlights the opportunity to unobtrusively gather market information from an international group of customers by providing Internet-based value-added services.
\end{abstract}

\section{Article Type:}

Case study

\section{Keyword(s):}

Market research; Internet; Financial services; International accounting; Credit cards; Expenses. 


\title{
Final version published: Journal of Business \& Industrial Marketing, Vol: 19, Number 3, Year 2004, pp: 178-187
}

\author{
An executive summary for managers and executive readers can be found at the \\ end of this issue
}

\section{Introduction}

The impact of the introduction of the World Wide Web (WWW) as a medium for conducting market research is little understood. Employing a case-study approach, we look at the application of WWW market research in the credit/charge card market for international payments. The case is exploratory in nature and, as a real world example, offers comparison with more traditional approaches to market research. The case demonstrates that the WWW provides an opportunity for companies to re-examine the ways in which they conduct market research. In addition, it shows how the innovative use of Internet-based research can be used to open up new business opportunities for even the smallest of companies.

This paper is structured as follows. The first section discusses the evolution of market research and puts forward the argument that we are now moving into a new phase of market research brought about by the advent of the Internet. In this section we also briefly outline the potential, and limitations, of the WWW as a medium for market research. Second, we present the case of Xenon Laboratories, focusing on their corporate background, the nature of the industry they are operating in, Xenon's approach to market research, the preliminary results generated by this approach, and potential commercial implications of the case. Finally, we conclude and discuss managerial implications.

\section{The evolution of market research}

Market research is concerned with the systematic and objective collection and evaluation of information about specific aspects of marketing problems in order to assist

management make effective decisions. However, market research is not an end in itself, it is a means to an end, the improvement of decision making (Chisnall, 1991). The better the quality of information that managers have at their disposal, all other things being equal, the lower the level of risk associated with strategic decision making.

The operationalization of market research has developed significantly over the last 30 years. The changes may be categorized into three main eras (see Table I). The process of development has already moved through two subtle but very different phases, and we are currently entering the third phase. This third and new phase is made possible only by developments in information technology (IT) and the introduction of the WWW.

Table I The phases of market research

\begin{tabular}{llll}
\hline & Phase 1 - 1960s & Phase 2 - 1980s & Phase 3 - late 1990s \\
\hline $\begin{array}{l}\text { Orientation } \\
\text { Data type }\end{array}$ & $\begin{array}{l}\text { Consumer marketing } \\
\text { Statistical quantitative }\end{array}$ & $\begin{array}{l}\text { Relationship marketing } \\
\text { Increasing focus on qualitative }\end{array}$ & $\begin{array}{l}\text { Interactive and adaptive marketing } \\
\text { Real-time data, quantitative } \\
\text { and qualitative }\end{array}$ \\
Sustomer target & $\begin{array}{l}\text { Mass market to segmented } \\
\text { market } \\
\text { Large samples of individuals }\end{array}$ & $\begin{array}{l}\text { Focus on existing customers } \\
\text { and relationship development } \\
\text { Often smaller samples of } \\
\text { dyads }\end{array}$ & $\begin{array}{l}\text { Individual buying unit } \\
\text { Highly-biased samples of } \\
\text { individual customers }\end{array}$ \\
\hline
\end{tabular}


The first phase consisted of what to many is still the typical approach to market research. It is typified by the content of many excellent text books on the process of "doing market research" (see, for example, Lehmann, 1985; Parasuraman, 1991). In this approach, buyers are seen as a mass of different market segments, knowledge about which can be gleaned through the use of large sample sizes.

The second phase in the development of market research was based largely on the initial work of the International Marketing and Purchasing (IMP) group in recognizing the role that relationships play in industrial marketing (e.g. Ford, 1980; Turnbull and Cunningham, 1981; Håkansson, 1982). This perspective has since been significantly widened to understand the role that relationships play in all buyer-seller environments (e.g. Christopher et al., 1991). This development required substantial changes to the ways in which market research studies were conducted, with the focus of attention shifted from the buyer to the buyer-seller dyad itself (see, e.g. Wilson, 1978; Anderson et al., 1994).

It has become increasingly apparent that we are entering a new phase of market research as a direct result of the developments in IT which are restructuring both markets and marketing (Naudé and Holland, 1996, 1998). Recent developments in areas such as database theory, information science, and data-warehousing have made possible a very different approach to marketing. As more and more supply chains and buyerseller relationships become based on the underlying electronic networks connecting them (see, e.g. Magretta, 1998), a different view of marketing and of market research is emerging.

The widespread availability of cheap and powerful IT means that it is now economically feasible to collect, store, analyse and share almost limitless amounts of marketing data concerning customer details, customer buying patterns, channels of distribution and the performance of economic partners. Large-scale databases, coupled with fast processors and high-speed networks, have effectively removed most geographic and time barriers previously associated with the transmission and processing of data. It is the development of this third phase of market research that has opened up potential opportunities for market researchers. In the next section we outline the opportunities and limitations of the WWW as a medium for market research.

\section{The WWW as a medium for market research}

The use of the WWW as a marketing business tool is well documented (see, e.g. Berry et al., 1994; Bianco, 1997; Loebbecke and Jelassi, 1997), but little research exists as to its full potential as a market research tool. While it is clear that the WWW will increasingly be used as a medium for conducting market research (Comley, 1996; Quelch and Klein, 1996; Cobanoglu et al., 2001), the full implications of its use are not yet fully understood.

Existing research has examined the implications of the WWW in terms of the potential dramatic reductions in the time and costs involved in testing new financial service products (Naudé et al., 1998; Lockett et al., 1999). Also, it has concentrated on comparing the costs, response rates and time horizons involved in conducting surveys via traditional mail versus electronic media (see Cobanoglu et al. (2001) for a review of the existing research). However, we view the introduction of the WWW as much more than an opportunity to merely reduce the time spans and costs involved in the market research process. As the following case will show, the WWW presents market 
researchers with an opportunity to re-evaluate their existing approaches to conducting market research.

The potential advantages of using the WWW are well-researched (Johnstone, 1999) and include greater speed, lower cost, improved accuracy in encoding data and the ease of obtaining international samples. Therefore, the potential to conduct large-scale market research projects may be facilitated by the introduction of the WWW. However, caution should be exercised in assuming that the benefits of the WWW are universal and apply to all forms of Internet-based market research. This has been a particular issue in relation to qualitative research (Pincott and Braithwaite, 2000). In addition, there are also potential limitations to performing quantitative market research using the WWW.

The WWW as a medium for market research may be limited by a number of different factors. The technical aspects of research include: poor response rates, unrepresentative samples and incorrectness of questionnaire self-completion (Kent and Lee, 1999; Schillewart et al., 1998). We comment on each of these different issues below.

The issue of poor response rates is linked to the human aspect of conducting market research. Brown et al. (2001) argue that the human element of conducting market research over the WWW is crucial to gaining good response rates. First, is the issue of achieving initial contact with businesses, which relates to the above issue of poor sample response rates. Second, is to consider how you are going to motivate a participant to respond using the WWW. Therefore, it is important to clearly work out how you are going to identify, contact and then motivate respondents. These issues are very important owing to the declining effectiveness of Internet advertising and direct emailing of potential respondents (Lockett and Blackman, 2001).

The issue of unrepresentative samples is a potential problem for Web-based surveys. Although Internet adoption has increased dramatically, the population of Internet users are not likely to be representative of the population at large. In particular, rates of Internet adoption vary considerably by country. Therefore, this creates a number of problems for constructing representative samples. However, it must be acknowledged that not all market research requires representative samples to generate generalizable results. Furthermore, a biased sample may be a desirable outcome, as data will be gathered from actual true Internet users (Pitkow and Kehoel, 1997; Schillewart et al., 1998).

Finally, the issue of incorrectness of questionnaire self-completion is a problem that is faced by all questionnaires that are not administered face to face. However, the Internet has opened up the potential to establish a direct line of contact with the respondent via e-mail. This is an advantage over mail-based surveys so that any potential confusion can be eliminated via dialogue (Schillewart et al., 1998). Therefore, merely transferring traditional questionnaire-based techniques to the Internet is not a sufficient condition for successful market research. It is important that market researchers develop alternative methods for conducting market research that may be better suited to the Internet.

\section{Xenon Laboratories and market research}

The objective of the case is to present a real-life example of how Xenon Laboratories, an Internet financial service provider, has used the WWW as a medium for market research. The case demonstrates that by employing a novel approach to market research, Xenon was able to collect data that would have been very difficult to collect employing more traditional methodological approaches. 


\section{Xenon Laboratories' background}

Xenon Laboratories (http://www.xe.net/) is a Canadian Internet financial service provider[1]. Xenon states that it aims to work in partnership with financial institutions in order to develop and deliver Internet-based international financial services for corporate clients. The initial focus of Xenon was to build a client base of importers and exporters that can be used to identify potential market opportunities, test product solutions and act as an initial distribution channel. This was achieved by pursuing a strategy of "symbiotic marketing" whereby they provide free Internet informational services in order to attract potential customers (see Lockett and Blackman, 2001, for an overview) and to gather market data.

The original launch of its Universal Currency Converter ${ }^{\mathrm{TM}}$ (http://www.xe.net/currency) in 1995, may be viewed as a "sweetener" used to identify any potential interested parties. The Universal Currency Converter ${ }^{\mathrm{TM}}$ is a simple service that converts an amount in a stated currency into a second currency and by March 2000 this service was performing over three million calculations each month. Xenon's currency converter was the second most popular on the market in terms of direct hits to the site (Lockett and Blackman, 2001). The popularity of the converter was due to the large number of Web sites that linked to the service to allow foreign customers to convert prices into their own currency (including eBay)[2].

In addition to this service, Xenon launched a complementary Currency Update Service ${ }^{\mathrm{TM}}$ (http://www.xe.net/currency/subscrib.htm) that forwards daily, via e-mail, a table of exchange rates to interested users, expressed against the user's choice of currency. This free service has enabled Xenon to generate a large database of customers receiving daily information on foreign exchange. To receive this service, customers must complete a registration page that provides Xenon with information about who the users are and how/why they use the service. Findings from the registration information have revealed that a considerable number of customers were using the service to process travel expense claims, the vast majority of which were international business travellers.

The objective of the research was to examine the revenue that existing providers of credit cards were generating for international payments made via credit and charge cards. More specifically, the market research investigated the non-visible charge taken by the company providing the credit card (the credit card issuer) for converting the value of a purchase into the currency of the customer[3]. While the annual account fees and interest rates for late payment are clearly stated by credit/charge cards, the additional charge for converting currency for foreign purchases is not easily obtainable.

There were two potential customer groups who may value this information. First, if the charges were large it was considered there may be an opportunity to advise large corporate customers, who commonly issue corporate cards to their employees, on negotiating lower fees for processing charge and credit card payments. Second, substantial charges for foreign exchange may provide a potential opportunity for companies collecting international payments by credit card. For example, international retailers (e.g. Internet-based retailers such as Amazon) could charge their customers in their local currency. This would remove the need for the customer's credit card issuer to convert the funds. In the next section we outline the market for credit/charge cards and international payments and develop specific research questions.

\section{The market for credit/charge cards}

Typically, an organization provides its employees with a credit/charge card that they can use to pay for travel and out-of-pocket expenses. Trade data from the main corporate card issuers suggest that employees use corporate cards rather than their own credit or charge cards to simplify the process of collecting expenses and avoid exceeding their 
personal credit limits. In addition, where the employee does not have access to a corporate card they would expect the company to bear the full cost of any transactions.

Purchasers of corporate credit cards are normally concerned with reducing the effort required to administer expense claims and access aggregated information about relationships with key vendors. The issuers of charge/credit cards have developed complex information systems to achieve two aims. First, to simplify their own administrative processes. Second, to reduce travel and expense budgets for clients, both by identifying potential abuses of expense claims and through negotiating lower prices from key vendors. However, the sophisticated information systems developed to reduce employee and vendor costs contrast with the opaqueness of the revenue sources to the issuer of the corporate card.

In the case of personal cards, customers borrowing from the card issuer generate the largest proportion of income. However, with corporate cards, where the expense bills are normally settled each month, this is not the case. Additional visible charges include the annual management fee charged to the corporate client (or the individual). In addition to the visible charge of borrowing, a significant proportion of the revenue is derived from hidden charges, which can be surprisingly high (Naudé et al., 1993). These hidden charges include a foreign exchange surcharge for foreign expenses (not traditionally negotiable even for multinational corporations) and a merchant acquisition charge for processing the payment (obviously not a charge to the corporation adopting the card).

The focus of the market research was to examine the foreign exchange charges that may be incurred when a payment is converted from the foreign currency of the charge to the domestic currency of the card holder. To develop a greater understanding of this market two key research questions were addressed:RQ1. = Do the card providers have the same charges for foreign exchange?RQ2.=Do the card providers' charges for foreign exchange vary between countries?The foreign exchange surcharge levied by the card issuer is determined by the difference in the foreign exchange rate used by the card issuer and the mid-rate achieved by the card issuer in the foreign exchange market on the date of the payment. The card issuers are either members of the two main credit card organizations (Mastercard and Visa) or the charge card American Express Group. Each of the payment processing organizations are able to net the currency flows among their credit card issuing members in different countries, which results in only a small portion of the total foreign exchange requirement being traded. As the exchange rate is applied by the payment organization before the transaction is sent to the issuer to debit the customer card, neither the credit card issuer or payment organization has the risk of the foreign exchange prices impacting the value of the funds collected. The rate the card issuer and the payment organization can achieve following the netting should be very close to the mid rate[4] achieved by the Interbank[5] market on a particular day to the size of their purchases. A close approximation of the foreign exchange surcharge of the card issuer can therefore be calculated using the information on the card statement and the mid-rate for the exchange rate in the Interbank market on the day of the payment (see the Appendix for the method of calculation).

We now describe how a traditional market research approach would be applied to the research questions outlined above. This approach will then be compared with Xenon's approach using the WWW as a medium for market research.

\section{Limitations of a traditional approach to market research}

In order to calculate the foreign exchange charge incurred in using a credit/charge card for making an international payment, details of both receipt for the original payment and the credit/charge card statement is required. The key difficulties in collecting the data using traditional methodologies include: 
- the identification;

- targeting;

- motivation to respond of international business travellers; and

- obtaining copies of both travel expense receipts and credit or charge card statements.

It was decided that a purposive sampling approach would be employed because the aim of the project was to describe and contrast the differences between the target groups; not to be able to generalise to a target population. (We would like to acknowledge an anonymous reviewer for this helpful point.)

Employing a traditional methodology, business travellers may be identified and approached for an interview, or sent a questionnaire, in either of two ways. First, faceto-face interviews could be conducted in locations where business travellers will pass through, e.g. hotels and airports. Alternatively, a mailing list may be purchased from a travel agency or airline and questionnaires could be mailed to respondents.

In this context, both methods were deemed to be unsatisfactory because they are likely to achieve a very low response rate. The anticipated low response rate is a function of a number of different barriers to conducting face-to-face interviews or utilizing mailed questionnaires. First, there is the problem of obtaining permission of the owner of the site (hotel or airport) to interview business travellers. Second, there are the costs associated with acquiring a suitable list of names to conduct postal research. Third, and perhaps most importantly, is the high informational requirement on the part of the respondent. This is because the immediate and simultaneous access to both expense receipts and credit/charge card statements is necessary to make the research meaningful. In addition, when using a traditional approach to market research, the high level of information required may also be perceived by respondents as being overly intrusive. The reluctance to provide all the information required, for reasons of privacy, may have an even greater detrimental impact on response rates.

Advertising the questionnaire on business travel sites on the Internet could offer a solution, with the travellers being incentivized to complete the questionnaire (e.g. providing airmiles for completing the questionnaire). While this could be a more efficient way to collect the data it is not clear how large an incentive would be required to encourage the business traveller to input the data. There is also the risk of bogus data being input in return for the incentive.

This approach highlights some of the problems associated with using traditional methods of market research. The use of the WWW to attract an audience does provide an advance on face-to-face interviews or mailings, since it does not require the support of other companies in the travel business. Furthermore, the cost and time involved in purchasing the Internet advertising, providing incentives and the risk of the collection of bogus data could be seen as prohibitive for exploratory research. The problems outlined above clearly eliminated the option of pursuing a traditional market research-based project for a small company like Xenon to collect the required market information.

\section{Xenon's alternative approach to market research using the WWW}

The following case demonstrates the way in which the WWW may provide a novel solution to many of the existing problems of conducting market research. The approach outlined below focused on market level rather than individual level data. To reassure the customers that their information would not be passed to third parties, Xenon did not collect any information that could identify the individual customer (i.e. cookies were not used). In addition, Xenon provided a clear privacy statement that information collected would only be used in an aggregated form. 
Some of the potential limitations of conducting market research using the WWW are outlined above. However, the approach taken by Xenon overcame the specific problems associated with: response rates, sampling and errors of self-completion. First, Xenon were able to generate a good response rate via providing free Internet informational tools. We outline the importance of this innovative approach in more detail below.

Second, and as outlined above, Xenon did not need to construct a representative sample of respondents because the aim of the project was to describe and contrast the differences between different target groups; not to be able to generalise to a target population. Third, any problems associated with response errors were effectively minimized by providing an easy-to-use service, which takes the respondent through a number of very simple clear steps when inputting the data. Also, where any potential confusion did arise, participants could easily e-mail a Xenon employee for a prompt response. We now focus on how Xenon developed their approach to market research.

Through the launch of a range of complementary services, Xenon has built up a large potential user base, which constitutes a sample of self-selecting individuals. The problem facing start-up firms using the Internet is how to attract customers to their Internet site. The traditional approach to driving traffic to a site has been through online (and offline) advertising. However, the costs involved in such a strategy have become increasingly prohibitive (see Lockett and Blackman, 2001). This has traditionally made the development of a significant Internet customer base a very expensive exercise. Furthermore, this problem is set to continue as the WWW becomes increasingly popular as a business-medium and competition for advertising space on key sites intensifies. Therefore, firms intending to use this channel must seek new ways of increasing their profile. Xenon has attempted to overcome this problem by devising the novel approach to targeting its customers by providing free informational tools (see Lockett and Blackman, 2001, for a discussion of this strategy).

The development (and continual expansion) of the customer base was an important first stage in the new product development/market research process. Without such a large (but cheaply generated and highly focused) target market, the subsequent market analysis, service development, testing and communication would be problematic. The information collected via firms registering for Xenon's free service has allowed Xenon to gain a better understanding of the market in which it is operating.

The questionnaire included in the Currency Update Service ${ }^{\mathrm{TM}}$ registration indicated that a significant proportion (11 per cent) of the customers' prime use of the e-mail service was to calculate travel expense claims. The original Universal Currency Converter ${ }^{\mathrm{TM}}$ service was of benefit to business travellers, because it increased the accessibility of the exchange rates and simplified the calculation. However, there was a risk that users were under-claiming their travel expenses because of two factors:

1. The exchange rate on the day the expense was claimed being different from the exchange rate on the day the payment was made.

2. The exchange rate applied by the credit card issuer being higher than the midrate used in the currency converter[6].

In order to overcome this problem the Travel Expenses Calculator ${ }^{\mathrm{TM}}$ (http://www.xe.com/tec/) was developed. This new tool allowed the business traveller to select the date the payment was made and to select the correct exchange rate to convert the charge. In addition, the Travel Expenses Calculator included a field for the customer to enter the percentage charge applied by the credit card issuer for converting the payment. As the business travellers typically did not have access to this information an additional service was developed. The Credit Card Charges Calculator ${ }^{\mathrm{TM}}$

(http://www.xe.com/ccc/) was developed and linked to the Travel Expenses Calculator $^{\mathrm{TM}}$. This service enabled customers to estimate the typical foreign exchange charges of their credit or charge card by inputting the details of a previous statement and the receipt for the expense. The new service was launched in April 1998 to enable 
business travellers to improve the accuracy of the converted value of an expense receipt in a foreign currency. Customers using the new service are able to input the date of the receipt to look up the appropriate exchange rate, and to calculate the foreign exchange charges of the credit or charge card used for the payment.

The introduction of the Travel Expenses Calculator ${ }^{\mathrm{TM}}$ and Credit Card Calculator ${ }^{\mathrm{TM}}$ has enabled Xenon to gain a much deeper understanding of the market for making international payments by credit/charge card. The development of the suite of services has given the company access to information that would not ordinarily be available, would be prohibitively costly or would take a very long time to collect. The introduction of the Credit Card Calculator ${ }^{\mathrm{TM}}$ has allowed Xenon to access unique "real-time" market data (in the sense of collecting it as soon as the user makes the currency conversion), an option that would not be available to it through any other form of media. The data that is collected, stored and provided while customers use the Credit Card Calculator ${ }^{\mathrm{TM}}$ includes the following:

- User's IP address - identity of owner of server used to access the service (i.e. AOL, company intranet);

- date;

- USD equivalent;

- receipt amount;

- receipt currency;

- date of receipt;

- value of claim;

- currency of claim;

- card type;

- bank;

- estimated charge (home currency) (for converting currency);

- value of charge; and

- per cent charge.

On the basis of this information it is possible to conduct basic market research by aggregating the inputted calculations. Xenon is now in a unique position to analyse whether or not the different card providers employ the same charging levels and whether or not these companies' charge structures vary according to geographical region. This opens up a new potential marketing opportunity for the company to cooperate with firms to negotiate a lower charge structure from the card supplier or identify the size of a potential opportunity for new market entrants to provide services to the businesses collecting international payments via credit/charge cards.

This approach must be contrasted with the dominant methodology of merely disseminating questionnaire-based research tools via e-mail. Although there are quantitative improvements to be made via distributing the questionnaire electronically, the problem of low response rates persists. This problem is exacerbated by increasing levels of junk e-mails, which are leading to a further deterioration in response rates (Lockett and Blackman, 2001). The value-added service-based approach of Xenon circumvents the problem of low response rates and association with junk e-mail. Respondents are inputting data into a service that is free and beneficial to them, thus increasing levels of participation and potentially enhancing the quality of response. This value-added approach, which is mutually beneficial to both parties, is an important and novel approach to market research. Such an approach helps to overcome problems associated with motivating the respondents to provide information as a clear incentive is provided. This has the associated benefit circumventing the traditional process of market research as both parties work together for their mutual benefit.

\section{Preliminary results}

As outlined, the launch of the Credit Card Calculator ${ }^{\mathrm{TM}}$ has provided a unique opportunity to collect real time market data. However, it was necessary to introduce a filter on the 
incoming data, as it became evident from the inputs that not all users were using the service properly. Therefore, the dataset had to be refined by the deletion of outliers and any multiple entries. In addition, all multiple entries were deleted because a number of users become impatient and will repeatedly send the same calculation, as the Internet does not always respond immediately. In total, nearly 6,000 observations have been logged, which have been used to address the research questions highlighted earlier.

On the basis of the information collected, it has been possible to begin to develop a greater understanding of the credit/charge card market for international payments. For simplicity of presentation, we have restricted the analysis below to the main three card processing associations rather than to individual credit card issuer's members, and to the most popular countries in the sample.

The first stage of the analysis was to compare the different card providers' charges by country. Therefore, separate ANOVA models were calculated for each of the countries listed in Table II. It was important to conduct the analysis on a country-by-country basis, so that the composition of each sample was consistent, and so country effects of the sample would not bias the results.

Table II Charging structures by card type

\begin{tabular}{|c|c|c|c|c|c|}
\hline Country & $\mathrm{N}$ & Card 1 Mean (SD) & Card 2 Mean (SD) & Card 3 Mean (SD) & ANOVA F Stat \\
\hline \multirow[t]{2}{*}{ USA } & 2,425 & 2.28 & 2.08 & 2.09 & $2.84^{*}$ \\
\hline & & $(2.16)$ & $(1.90)$ & $(1.84)$ & \\
\hline \multirow[t]{2}{*}{ UK } & 779 & 3.35 & 2.87 & 3.26 & $4.37^{* *}$ \\
\hline & & $(1.73)$ & $(1.81)$ & $(1.17)$ & \\
\hline \multirow[t]{2}{*}{ Canada } & 684 & 2.41 & 2.37 & 2.70 & 1.59 \\
\hline & & $(1.88)$ & $(2.17)$ & $(2.20)$ & \\
\hline \multirow[t]{2}{*}{ Germany } & 88 & 3.31 & 2.61 & 3.50 & 0.73 \\
\hline & & $(2.45)$ & $(2.44)$ & $(2.36)$ & \\
\hline \multirow[t]{2}{*}{ France } & 188 & 2.87 & 2.91 & 1.97 & $5.70^{* * *}$ \\
\hline & & $(2.08)$ & $(1.66)$ & $(1.01)$ & \\
\hline \multirow[t]{2}{*}{ Australia } & 212 & 2.68 & 2.01 & 2.51 & 1.14 \\
\hline & & $(2.18)$ & $(2.27)$ & $(1.67)$ & \\
\hline \multicolumn{6}{|c|}{ Notes: Significance levels: ${ }^{*} p<0.1 ;{ }^{* *} p<0.05 ;{ }^{* *} p<0.01$} \\
\hline
\end{tabular}

The results in Table II indicate that there is some variation in the charging structures employed by the different card providers. This was found to be the case in the USA (significant at the 10 per cent level), UK (significant at the 5 per cent level) and France (significant at the 1 per cent level). The next stage of the analysis was to examine each of the different card providers' charging structures individually to see if their charging structures varied between countries. Again, ANOVA analysis was performed in order to investigate this issue, the results of which are presented in Table III. 
Table III Charging structures by countries

\begin{tabular}{lccc}
\hline & $\begin{array}{c}\text { Card 1 Mean } \\
(\text { SD })\end{array}$ & $\begin{array}{c}\text { Card 2 Mean } \\
\text { (SD) }\end{array}$ & $\begin{array}{c}\text { Card 3 (Mean } \\
\text { (SD) }\end{array}$ \\
\hline $\mathrm{N}$ & 2,200 & 718 & 1.458 \\
USA & 2.28 & 2.08 & 2.09 \\
UK & $(2.16)$ & $(1.90)$ & $(1.84)$ \\
& 3.35 & 2.87 & 3.26 \\
Canada & $(1.73)$ & $(1.81)$ & $(1.17)$ \\
& 2.41 & 2.37 & 2.70 \\
Germany & $(1.88)$ & $(2.17)$ & $(2.20)$ \\
& 3.31 & 2.61 & 3.50 \\
France & $(2.45)$ & $(2.44)$ & $(2.36)$ \\
& 2.87 & 2.91 & 1.97 \\
Australia & $(2.08)$ & $(1.66)$ & $(1.01)$ \\
& 2.68 & 2.01 & 2.51 \\
ANoVA F Stat & $(2.18)$ & $(2.27)$ & $(1.67)$ \\
Note: Significance level: * & $p<0.001$ & $4.33^{*}$ & $17.15^{*}$ \\
\hline
\end{tabular}

The results in Table III indicate that there is a degree of variation in the charging structures of card providers across countries. For all three of the cards that we examined a significant difference was found between the mean charges across the different countries, all ANOVA models being highly significant at the 0.01 per cent level. By examining Table III it is possible to see that the mean charges vary (on average) by over a percentage point between the USA and UK across the three different card providers.

This preliminary analysis of the data indicates that there are substantial hidden foreign exchange charges levied on the use of credit/charge cards for international payments. Furthermore, the analysis provided us with answers to our two central research questions. First, there is some variation in the different card providers' charging structures within a country. This was found to be the case in USA, UK and France. Second, there are great variations in the charges levied by card providers across countries. However, this is only a preliminary stage of analysis. As the size of the dataset increases it will be possible to investigate a much broader set of research questions, when we are not restricted by the problem of limited degrees of freedom.

\section{Potential commercial implications}

The research showed that the charges for converting the foreign exchange are significant and reasonably consistent within a country. Therefore, large multinationals with significant travel budgets are incurring substantial foreign exchange charges from card issuers. Although it is possible to argue that, to an extent, these charges are offset by 
the value-added expense management services provided by the credit card issuers, potential substantial savings still remain.

In addition, there is an opportunity for the larger retailers (e.g. Amazon) to charge the customer in their own currency after adding an equivalent or slightly lower cost for converting the currency, and then converting the currency through the wholesale markets at a lower rate. The potential financial savings are significant. Using published information from Amazon's accounts an estimate of the value of savings can be made[7]. Sales that involve an international payment, involving a currency conversion are valued at (a very conservative estimate) approximately $\$ 53$ million per quarter from the US Web site alone. According to Xenon's market research, the income being captured by the credit card issuers for converting the currency of the payments for their customers is approximately 2.5 per cent of the value, or $\$ 1.3$ million, for the quarter. Given the low comparative cost for the wholesale conversion of currency, this would provide a significant opportunity for either Amazon, or a specialist supplier, to convert the payments on behalf of the customers and capture the 2.5 per cent charge from the credit card issuers. Alternatively, they could pass on any savings to the customer to enhance customer loyalty.

\section{Conclusions}

This paper has demonstrated how developments in IT and the WWW are leading to a reevaluation of existing best practice in the field of market research. Our contention, which is supported by the case material, is that we have entered a third phase of market research. Furthermore, developments in IT and the WWW are providing companies with the opportunity to re-examine the way in which they generate, handle and analyse marketing information, not only in terms of internal data, but also in terms of primary data. The case demonstrates that Xenon, by adopting an innovative methodological approach, has been able to collect data which would have been very costly, timeconsuming or simply not available with the use of a more traditional approach to market research. We feel that there are two important conclusions that arise from the case.

First, the identification and development of a customer base, via a strategy of offering complementary WWW-based services, is the key element of this new approach. Without the user base for Xenon's services the market research project would be very costly and time-consuming. The building of the customer base is an issue that any firm faces on the Internet and the issue of how to drive traffic to those services becomes an issue of paramount importance.

Second, by not employing a questionnaire-based methodology, the case demonstrated the feasibility of conducting market research using a non-intrusive research vehicle. This approach of providing a value-added service in the data collection process is important, as this minimizes motivational problems for respondents. Furthermore, a mutually beneficial relationship is fostered and developed between Xenon and the client, which facilitates the flow of information between parties.

There are also some interesting managerial implications to arise from the case of Xenon. First, there are a number of advantages for financial service providers in using this new channel of communication. These advantages combine to both lower the cost of market research and yet increase its usefulness. Once a customer database has been built up, based on the use of a suite of complimentary services, it becomes possible to access real-time market data to establish a greater understanding of a market. This is an important development on more traditional models of marketing, and market research, as it results in the development of a clear method of communication with potential customers. Also, these relationships are fostered and developed through a mutually beneficial exchange. 
Second, the methodology makes the exploration of an international market feasible for very small companies with limited cash resources but the patience to build a client base and gather market information with value-added services.

Finally, while the techniques can be used by smaller companies to identify market opportunities, they need to enter into commercial partnerships or raise the funding to develop product solutions that generate a commercial benefit. Recent changes in the capital markets suggest the key will be to use the information to build commercial relationships with larger organizations that have the resources to deliver commercial solutions.

\section{References}

Anderson, J.C., Håkansson, H., Johanson, J. (1994), "Dyadic business relationships within a business network context", Journal of Marketing, Vol. 58 pp.1-15.

Berry, J., Verity, J.W., Kerwin, K., De George, G. (1994), "Database marketing", Business Week, No.5 September, pp.34-40.

Bianco, A. (1997), "Virtual bookstores start to get real", Business Week, No.27 October, pp.146-8.

Brown, J., Culkin, N., Fletcher, J. (2001), "Human factors in business-to-business research of the Internet", International Journal of Market Research, Vol. 43 No.4, pp.425-40.

Chisnall, P.M. (1991), The Essence of Marketing Research, Prentice-Hall, Englewood Cliffs, NJ, .

Christopher, M., Payne, A., Ballantyne, D. (1991), Relationship Marketing, ButterworthHeinemann, Oxford, .

Cobanoglu, C., Warde, B., Moreo, P.J. (2001), "A comparison of mail, fax and Web-based methods", International Journal of Market Research, Vol. 43 No.4, pp.441-52.

Comley, P. (1996), "Internet surveys: the use of the Internet as a data collection method", Proceedings of the ESOMAR/EMAC Symposium on Research Methodologies for the New Marketing, ESOMAR Publication Series, Vol. 204 pp.335-46.

Ford, D. (1980), "The development of buyer-seller relationships in industrial markets", European Journal of Marketing, Vol. 14 No.5/6, pp.339-54.

(1982), in Håkansson, H. (Eds), International Marketing and Purchasing of Industrial Goods, John Wiley \& Sons, New York, NY, .

Kent, R., Lee, M. (1999), "Using the Internet for market research: a study of private trading on the Internet", Journal of the Market Research Society, Vol. 41 No.4, pp.377-85.

Lehmann, D. (1985), Market Research and Analysis, Richard D. Irwin, Homewood, IL, . Lockett, A., Blackman, I. (2001), "Strategies for building a customer base on the Internet: symbiotic marketing", Journal of Strategic Marketing, Vol. 9 pp.47-68. 
Lockett, A., Blackman, I., Naudé, P. (1999), "Using the Internet/WWW for the real time development of financial services: the case of Xenon Laboratories", Journal of Financial Services Marketing, Vol. 3 No.2, pp.161-72.

Loebbecke, C., Jelassi, T. (1997), "Concepts and technologies for virtual organizing", European Management Journal, Vol. 15 No.2, pp.138-46.

Magretta, J. (1998), "The power of virtual integration: an interview with Dell Computers' Michael Dell", Harvard Business Review, No.March/April, pp.73-84.

Naudé, P., Holland, C. (1996), "Business-to-business relationships", in Buttle, F. (Eds), Relationship Marketing, Theory and Practice, Paul Chapman Publishing, London, pp.40-54.

Naudé, P., Holland, C. (1998), "Marketing in the information domain", in Halinen-Kaila, A., Nummela, N. (Eds), Interaction, Relationships and Networks: Visions for the Future, Proceedings of the 14th Annual IMP Conference, pp.245-62.

Naudé, P., Blackman, I.D., Dengler, S. (1998), "Real-time new product development in financial services: some managerial implications", in Sprague, R.H., Nunamaker, J.F. (Eds), Proceedings of the 31st Hawaii International Conference on System Sciences, .

Naudé, P., Lockett, A.G., Blackman, I.D. (1993), "Evaluating a financial service opportunity via judgemental modelling", International Journal of Service Industry Management, Vol. 4 No.4, pp.25-41.

Parasuraman, A. (1991), Marketing Research, Addison-Wesley, Reading, MA, .

Pincott, G., Braithwaite, A. (2000), "Nothing new under the sun?", International Journal of Market Research, Vol. 42 No.2, pp.137-55.

Pitkow, J., Kehoel, C. (1997), "GVU's WWW user surveys", available at:

www.gvu.gatech.edu, .

Quelch, J.A., Klein, L.R. (1996), "The Internet and international marketing", Sloan Management Review, Vol. 37 No.3, pp.60-75.

Schillewart, N., Langerak, F., Duhamel, T. (1998), "Non-probability sampling for WWW surveys: a comparison of methods", Journal of the Market Research Society, Vol. 40 No.4, pp.307-22.

Turnbull, P.W., Cunningham, M.T. (1981), International Marketing and Purchasing, Macmillan, London,

Wilson, D.T. (1978), "Dyadic interactions: some conceptualizations", in Bonoma, T.V., Zaltman, G. (Eds), Organisational Buying Behavior, American Marketing Association, Chicago, IL, .

\section{Further Reading}

Mehta, R., Sivadas, E. (1995), "Comparing response rates and response content in mail versus electronic mail surveys", Journal of the Market Research Society, pp.429-39. 


\section{Appendix}

The charge for foreign exchange was calculated using the following equation:Equation 1 where $x$ is the value of expense in currency of credit card statement $A$;

$y$ is the value of expense receipt in currency of expense B; and

$z$ is the published exchange (mid) rate on day of expense.

$$
\text { Per cent charge }=\frac{y-(x . z)}{y}
$$

